\title{
Cone-Beam Three-Dimensional Dental Volumetric Tomography in Dental Practice
}

\author{
Suzan Cangul ${ }^{1}$, Ozkan Adiguzel ${ }^{2}$ \\ ${ }^{1}$ Dicle University, Faculty of Dentistry, Department of Restorative Dentistry, Diyarbakir, Turkey \\ ${ }^{2}$ Dicle University, Faculty of Dentistry, Department of Endodontics, Diyarbakir, Turkey
}

\section{Correspondence:}

Dr. Suzan CANGUL

Dicle University, Faculty of

Dentistry, Department of

Restorative Dentistry, 21280,

Diyarbakir, TURKEY.

e-mail:suzanbali@outlook.com

Received 11 July 2017

Accepted 13 November 2017

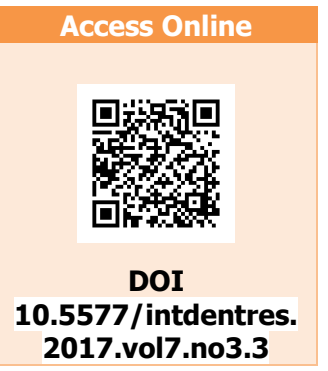

\begin{abstract}
Imaging methods are of great importance for diagnosis and treatment in dentistry. With technological advances, great progress has been made in these methods. Over time, 3-dimensional (3-D) imaging has replaced 2-dimensional, thereby providing examination of objects in all directions. Of these methods, which play an important role in the clinical evaluation of patients, cone-beam computed tomography (CBCT) is the newest and most advanced imaging method. This method will revolutionize dental in comparison with conventional $\mathrm{CT}$, it has several advantages, including a shorter scanning time, low radiation dose, low cost and the acquisition of high-resolution images. With 3-D imaging technology, this method has introduced the possibility of applying several procedures from diagnosis in the maxillofacial region to operative and surgical procedures. Although very clear results are not obtained from the imaging of soft tissues, the most important advantage of this technology is the capability of imaging hard and soft tissues together.
\end{abstract}

Keywords: Cone-beam computed tomography, CBCT, dental volumetric tomography, maxillofacial structure, three-dimensional imaging

How to cite this article: Cangul S, Adiguzel O. Cone-Beam Three-Dimensional Dental Volumetric Tomography in Dental Practice. Int Dent Res 2017;7:62-70.

\section{Introduction}

Dental radiography, which was first used in 1896, has become an important component in the evaluation of patients with dental problems (1).
From the initial taking of only an intra-oral image, with the development over time of 2-dimensional panoramic radiographs, it also became possible to take images outside the mouth. 
The use of more advanced imaging methods is limited by disadvantages such as high costs, high radiation doses and difficulties in accessibility. Over time there was an increasing need for new systems. The introduction of panoramic radiographs made it possible to image the jaws and maxillofacial structures on a single film. Due to negative features such as distortion, magnification and superimposition on 2-dimensional images, it was attempted to develop 3-D imaging techniques. Together with the recent use of computed tomography (CT), positron emission tomography (PET) and magnetic resonance imaging (MRI), conebeam computed tomography (CBCT) has now started to be widely used (2).

\section{Cone-Beam Computed Tomography (CBCT)}

This system, which was developed for angiography in 1982 started to be used subsequently for the imaging of maxillofacial structures. This device, which was known as digital volume tomography (DVT), was introduced into dental radiology as NewTom QR-DVT 9000 (NIM s.r.1, Verona, Italy) in 1998, and was developed to compensate for the limitations of the CT scanning machine (Fig. 1). In this method, which was developed as an alternative to $\mathrm{CT}$, a cone-shaped light source is used which provides reconstruction of the head and neck region (3).
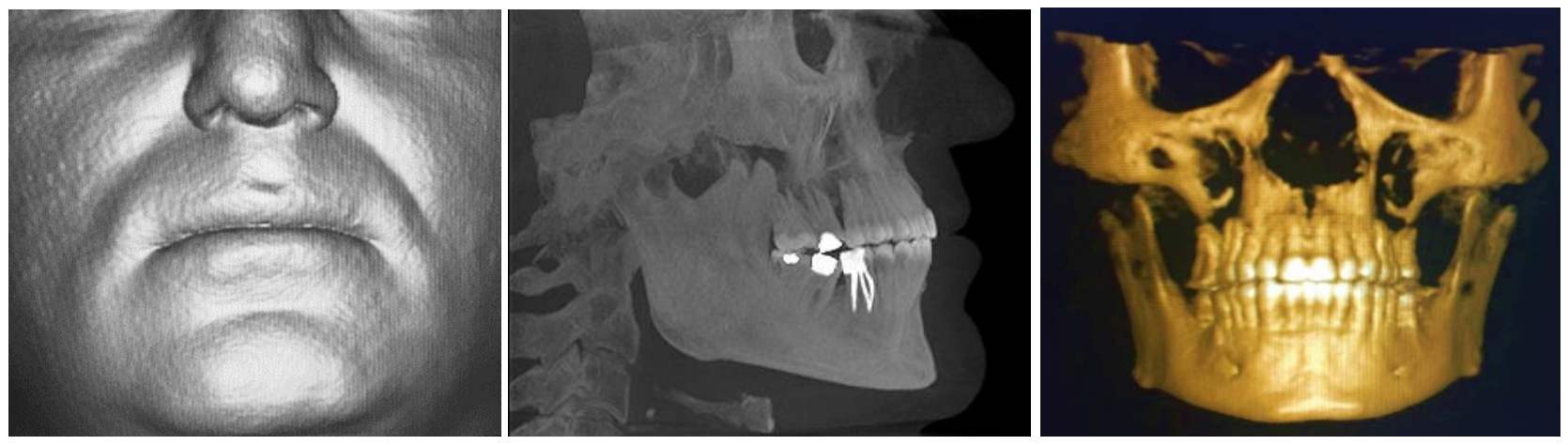

Figure 1. CBCT images of the patient from different angles

The most important feature of CBCT technology, which combines conventional x-rays with computerized volumetric reconstruction, is that images can be created corresponding to the various planes of axial, sagittal and coronal, from the volumetric data produced by the revolving light source $(4,5,6)$. Compared to 2-D radiographs, there are several advantages to this method that is being used with increasing popularity in dentistry to obtain 3-D images. As it is a particularly sensitive and accurate method, it provides more information than 2-D images, the radiation dose is lower and it has 2-D digital sensors $(7,8)$.

When radiographic examinations are examined, the effective radiation dose has been reported as 33-84 $\mu \mathrm{Sv}$ in serial radiographic examination and as 4.7-14.9 $\mu \mathrm{SV}$ per scan in digital panoramic radiographs $(9,10)$. In $C B C T$, the effective radiation dose has been reported to be $98 \%$ less than that of conventional CT and 2-4-fold equivalent of panoramic radiographs $(9,11,12)$. Different makes of CBCT may show differences in the effective radiation doses (Table 1$)(7,13)$. In examination of the maxillofacial region, the highest effective radiation dose with a wide field of view (FOV) scan has been determined as $1073 \mu \mathrm{Sv}$ on the CB MercuRay device, and the lowest as $19 \mu \mathrm{Sv}$ on the Kodak 9000 3-D device. Thus, there is approximately a 500 -fold difference between the highest and lowest effective doses.

To reduce the effects of radiation, the intensity of the $x$-rays coming from the $x$-ray device must be reduced and the capture speed of the image receptor and collimation must be increased. 
Table 1: Effective doses from different $C B C T$ units

Maxillofacial region (large FOV) Dentoalveolar region (medium FOV)

Localized region (small FOV)

\begin{tabular}{|c|c|c|c|c|c|}
\hline CBCT units & $\begin{array}{c}\text { Effective } \\
\text { dose ( } \mu S v)\end{array}$ & CBCT units & $\begin{array}{c}\text { Effective } \\
\text { dose ( } \mu S v)\end{array}$ & CBCT units & $\begin{array}{c}\text { Effective } \\
\text { dose ( } \mu S v)\end{array}$ \\
\hline NewTom $3 G^{a}$ & 68 & CB Mercuray panoramic FOV ${ }^{a}$ & 560 & CB Mercuray I FOV maxilla ${ }^{a}$ & 407 \\
\hline CB Mercuray standard quality ${ }^{a}$ & 569 & Next Generation i-CAT landscape & 87 & Promax 3D large adult ${ }^{\mathrm{a}}$ & 652 \\
\hline Next Generation i-CAT portrait mode ${ }^{a}$ & 74 & Galileos default exposure ${ }^{a}$ & 70 & PreXion 3D standard exposure ${ }^{a}$ & 189 \\
\hline Illuma standard ${ }^{a}$ & 98 & Galileos maximum exposure ${ }^{a}$ & 128 & PreXion 3D high resolution ${ }^{a}$ & 388 \\
\hline Illuma ultra & 498 & & & & \\
\hline Galileos Comfort $^{\mathrm{b}}$ & 84 & 3D Accuitomo $170^{\mathrm{b}}$ & 54 & 3D Accuitomo 170 (lower jaw, molar region) ${ }^{b}$ & 43 \\
\hline i-GAT Next Generation ${ }^{b}$ & 83 & i-GAT Next Generation ${ }^{b}$ & 45 & Kodak 9000 3D (upper jaw, front region) & 19 \\
\hline Illuma Elite ${ }^{b}$ & 368 & Veraviewepocs 3D ${ }^{\mathrm{b}}$ & 73 & Kodak 9000 3D (lower jaw, front region) ${ }^{b}$ & 40 \\
\hline Kodak $9500^{\mathrm{b}}$ & 136 & Kodak $9500^{\mathrm{b}}$ & 92 & Pax-Uni 3D (upper jaw, front region) ${ }^{\mathrm{b}}$ & 44 \\
\hline NewTom VGi ${ }^{b}$ & 194 & NewTom VGi ${ }^{b}$ & 265 & & \\
\hline NewTom VG & 83 & Picasso Trio (high dose) ${ }^{\mathrm{b}}$ & 123 & & \\
\hline \multirow[t]{5}{*}{ SkyView $^{\mathrm{b}}$} & 87 & ProMax 3D (high dose) ${ }^{b}$ & 122 & & \\
\hline & & ProMax 3D (low dose) ${ }^{b}$ & 28 & & \\
\hline & & Scanora 3D (upper jaw) ${ }^{\mathrm{b}}$ & 46 & & \\
\hline & & 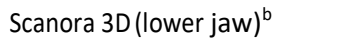 & 47 & & \\
\hline & & Scanora 3D (both jaws) ${ }^{b}$ & 45 & & \\
\hline
\end{tabular}

${ }^{a}$ Data from the study by Ludlow et al (2008), ${ }^{b}$ Data from the study by Pauwels et al (2012) (14)

In the CBCT unit, the image of the whole maxilla and mandible is taken with a single rotation of the device. The costs of CBCT are lower compared to other CT devices $(15,16)$.
Furthermore, while a normal CT device captures data in a fan shape, in the CBCT it is captured volumetrically (Fig. 2).

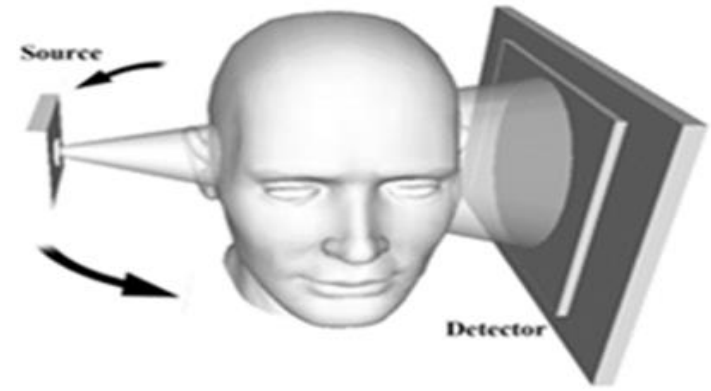

A

Cone shaped $\mathrm{x}$-ray beam

$\mathrm{X}$ and $\mathrm{Y}$ axis detector types

Only one or two 360 degree rotations

Low radiation dose

Examination speed is fastest

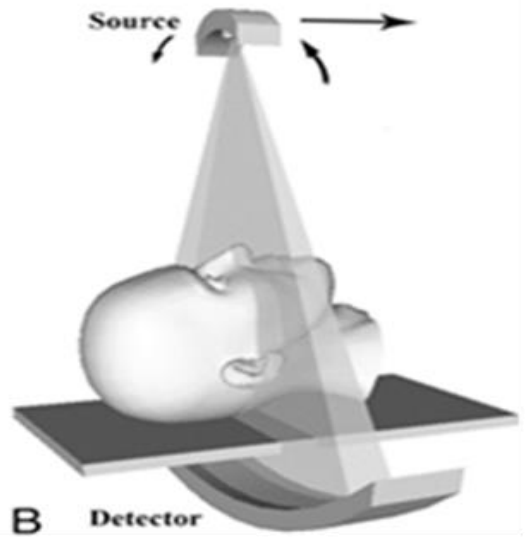

Fan shaped $x$-ray beam Only $X$ axis detector type Hundreds of rotations High radiation dose Examination is fast

Figure 2. Images showing the differences between the data capturing systems of normal CT and CBCT. A) The CBCT device captures data volumetrically

B) The CT device captures data in a fan shape (17) 
One of the most important features differentiating $\mathrm{CBCT}$ from $\mathrm{CT}$, is that in the presence of metal (metallic restoration, crown or implant), the quality of the CBCT image is not affected by distortion or artefacts that are created by metal, which in turn makes diagnosis more difficult (18). In a study by Guerrero et al (19), in which the properties of CT and CBCT were compared, it was reported that CBCT was the more advantageous technique in examinations of cost, radiation dose, weight and size.

CBCT is a digital device and it uses a computer program to form a 3-D volume from a series of 2-D images. Voxel is preferred to pixel in the terminology on the subject of volume. As the axial height of voxels of medical CT have been defined with a row thickness of $1-2 \mathrm{~mm}$, it is anisotropic, whereas in contrast, the voxels of CBCT are in the form of a complete bowl $(11,20)$.

In the DICOM (digital imaging communication in medicine) standard, which is universal for the 3-D imaging system, the files are processed as "dcm" rather than "tiff" or "jpeg".

The area that the clinician wishes to evaluate is a 3-D volume and is defined as the region of interest (ROI). The smaller the ROI image obtained, the better the resolution, as the resolution is related to the size of the image area (21). The resolution of CBCT images varies between 0.1 and $0.5 \mathrm{~mm}$.

CBCT systems can be classified into 2 groups as limited (dental or regional) and full (orthopedic or facial). The diameter of the FOV of limited CBCT varies between $40-100 \mathrm{~mm}$, while in full CBCT, this value is $100-200 \mathrm{~mm}$. Another important difference between these two types is that the voxel values in the limited type are smaller than those of the full CBCT $(0.1-0.2 \mathrm{~mm}$ or $0.3-0.4$ $\mathrm{mm})$. As the limited type has higher resolution, it is more suitable for endodontic use $(11,14,22)$.

\section{Areas of Use for CBCT}

CBCT devices which were first introduced in the 1990s for the imaging of dentomaxillofacial tissues, have many areas of use. These are: (23)

a. Maxillofacial surgery

b. Implant planning

c. Determination of the localization and size of pathological structures

d. Embedded teeth

e. TMJ morphology and pathologies

f. Evaluation of paranasal sinuses

g. Evaluation of the height and volume of alveolar bone h. Root canal morphology and the relationship of the roots to the surrounding tissues

i. Airway analysis

j. Determination of the cleft borders in patients with a cleft palate

k. Diagnosis of inflammatory and degenerative diseases

I. Determination of odontogenic and nanodontogenic cysts and tumors

$\mathrm{m}$. Determination of dental anomalies such as ectopic or supernumary teeth

\section{n. Diagnosis of periodontal diseases}

When current areas of CBCT use are examined, it is seen to be used most frequently in the evaluation of the bone structure before implant placement. Due to the cross-sectional slices, this method provides reliable information about the location of important anatomic formations and provides information explaining the height and width of the alveolar bone. Especially in implant applications, the surgical implant allows the formation of a guide stent. The use of these stents makes the surgical intervention minimally invasive, reduces postoperative pain and swelling and allows placement of the prostheses in the mouth in a short time (24).

CBCT technology has been developed to provide treatment strategies in invasive surgical interventions at a minimum level (25). Especially for the determination of the locations of intra-oral anomalies, this device has started to be used in routine dental examinations in some centers in the USA. Recent research has reported that CBCT use has increased for the visualization of intra-oral anomalies such as embedded teeth, oral cysts and supernumary teeth.

Together with developments in CBCT, difficulties have been removed from airway analysis and CBCT technology has replaced lateral cephalograms providing 2-D images used in the past as they did not provide accurate results.

The use of CBCT in orthodontics has increased with the advantages presented by two and three-dimensional cephalometric images. The accuracy rate of measurements, the clear examination of dentoskeletal structures and the evaluation of soft tissue relationships have increased with the use of this device (6). As scanning time is shorter than 1 minute, this is also an advantage for patients (26).

To prevent nerve damage in the relationship between the inferior alveolar canal and the third molar teeth of the lower jaw, 3-D images should be taken. CBCT is recommended for this purpose (Fig. $3)$. 

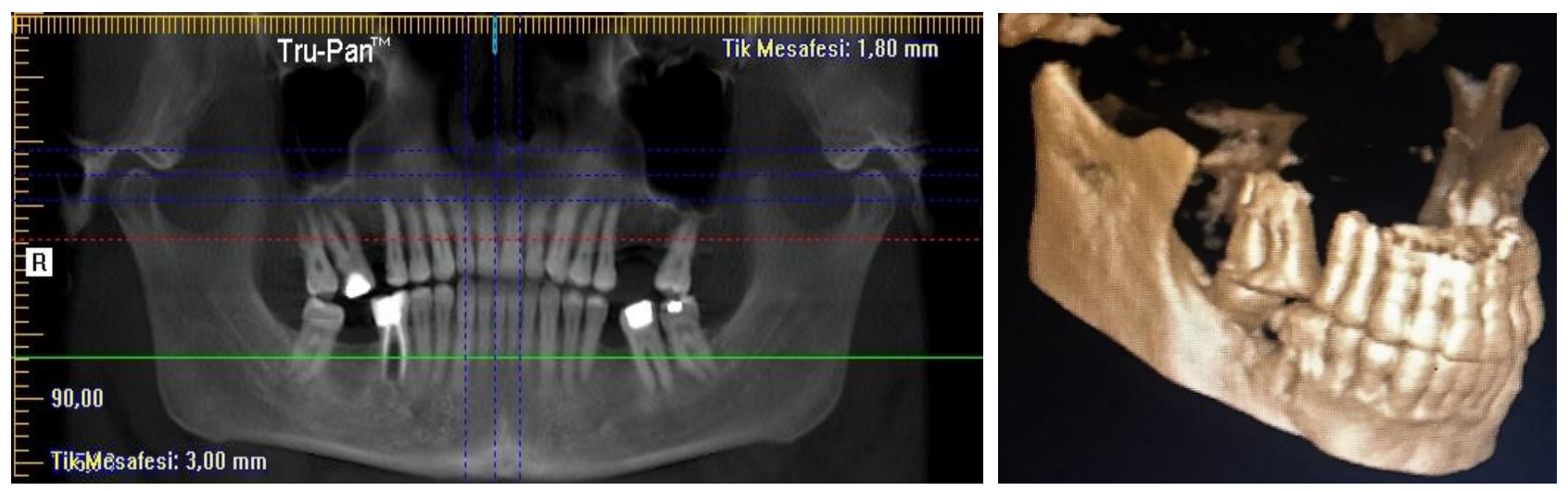

Figure 3. 2-D and 3-D images of a patient evaluated with CBCT.

Other important areas of use of $\mathrm{CBCT}$ include the diagnosis of temperomandibular joint (TMJ) diseases, determination, measurement and treatment of tumors in the jaw, determination of bone structure and tooth orientation, identifying the source of pain and pathologies and for reconstructive surgery. Fullmer et al (27) examined the $\mathrm{CBCT}$ results in persistent, chronic, suppurative osteomyelitis of the mandible and reported that CBCT could be used as a guide for the surgical process. In another study in 2008 by Madrigal et al (28), the efficacy of CBCT was compared with panoramic radiographs in the evaluation of bone stock before an implant application, and it was concluded that CBCT was the more advantageous method.

In the examination of the TMJ with CBCT, the shape, size and position of the condyle heads is evaluated. The difference from lateral cephalometric films is that the image is taken not only from the lateral, but axial and frontal slices can also be taken (29). In 2007, Honey et al evaluated the relationship between the presence of pathological formations in the TMJ and the adjacent anatomic structures and used CBCT imaging which permitted detailed examination without superpositioning (30).

CBCT is often used in endodontics and is mostly used to examine the relationship between the canal wall and canal filling materials. Alencar et al examined canal fillings prepared with the $\mathrm{Ni}-\mathrm{Ti}$ rotary systems, the root resorption and broken instrument parts by comparing periapical radiographs and CBCT. There were found to be statistically significant differences between the two imaging methods (31).

\section{The Advantages and Disadvantages of CBCT}

CBCT provides extremely good results in the imaging of craniofacial structures. It is also an extremely useful method giving clear results in the evaluation of high contrast structures and bones $(32,33)$. Although there are still some drawbacks in soft tissue imaging, it is being directed towards the development of software algorithms and techniques with the aim of increasing the contrast. The use of CBCT technology in clinical applications has several advantages compared to conventional CT.

The first of these advantages is that a better quality image is produced by reducing the scattered radiation of the focussed $x$-ray bundle. As it is a single scan, various views and angles are produced which can be manipulated to provide a more comprehensive evaluation. The major advantage of $\mathrm{CBCT}$, which provides pain-free, non-invasive and accurate results, is that it has the capacity to image bones and soft tissue at the same time. Most CBCT units can be adjusted to scan a specific area and when necessary, it has the ability to scan the whole craniofacial complex. No radiation remains in the patient's body after imaging. Previous reports have stated that the radiation dose in $\mathrm{CBCT}$ is reduced by $98 \%$ compared to conventional CT $(12,34,35)$.

Each volumetric data set in $\mathrm{CBCT}$ includes a 3-D block known as voxels and represents x-ray absorption at a specific level. The size of these voxels affects the resolution of the image. As CBCT has high resolution, the clarity of the image is better and more accurate results are obtained. When all the systems related to CBCT are examined, it can be seen that they have been set so that the scanning duration does not exceed 1 minute. By gathering the data rapidly, the possibility of the formation of movement artefacts is reduced (36). 
That the volumetric data in CBCT are isotropic means that the image voxels are the same in 3 dimensions. This makes it possible to make clear measurements and evaluations according to the anatomic characteristics of the patient (37).

Another advantage of CBCT technology is the low level of metal artefacts in secondary reconstructions designed to examine the teeth and jaws. To achieve this, manufacturers have developed algorithms for the prevention of artefacts (38). In respect of disadvantages, although the likelihood of exposure to excessive radiation is always low, there still remains a risk of cancer. However, the benefit of accurate diagnosis greatly outweighs the risk. The effective radiation dose of CBCT varies according to criteria such as the related area, resolution and FOV. All these parameters must be selected carefully to reduce the exposure of the patient to radiation (39).

Another significant disadvantage of CBCT is that the limited contrast resolution shown in the imaging of soft tissue does not provide as good results as for hard tissue (40).

\section{Limitations to the Use of СВCT}

For the correct and reliable use of CBCT, good training is mandatory. The American Oral and Maxillofacial Radiology Academy and the European Dentomaxillofacial Radiology Academy have stated the necessity for CBCT to be applied by a practitioner who has undergone sufficient training $(41$, 42). Moreover, each CBCT scan must be presented together with an imaging report.

As CBCT is a guide for patient treatment, images must be taken after clinical examination has been made and a history established for the patient. The 3-D images formed will contribute to the potential progress of the patient.

\section{CBCT Systems Used in Dentistry}

There are 5 CBCT systems which have been approved for use in dentistry, which show differences in respect of size, settings, FOV and clinical use. These systems are NewTom 3G (Qualitative Radiology), i-CAT (International Imaging Sciences), CB MercuRay (Hitachi Medical Institute), 3D Accuitomo (J. Morita Production) and ILUMA (IMTEC Imaging) (21).

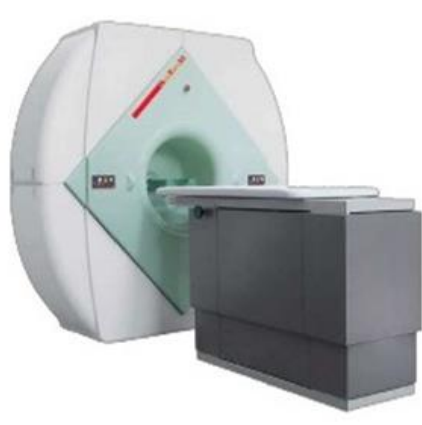

A)

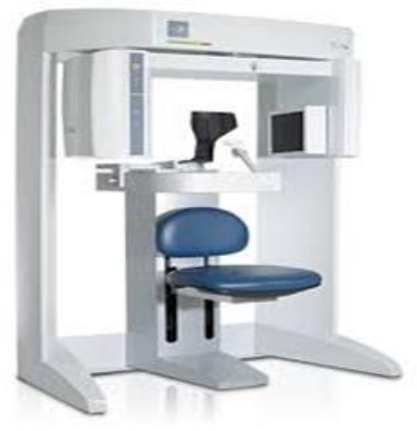

D)

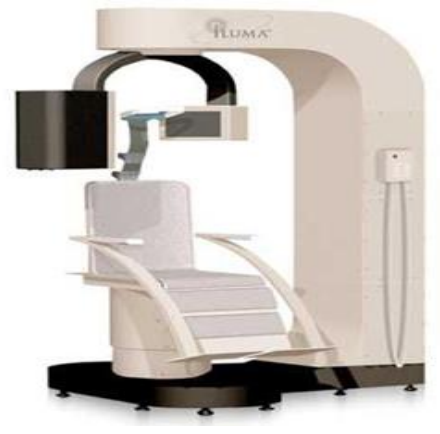

B)

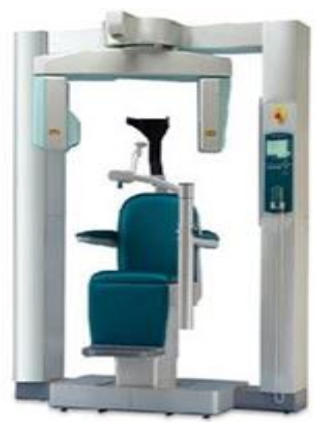

E)

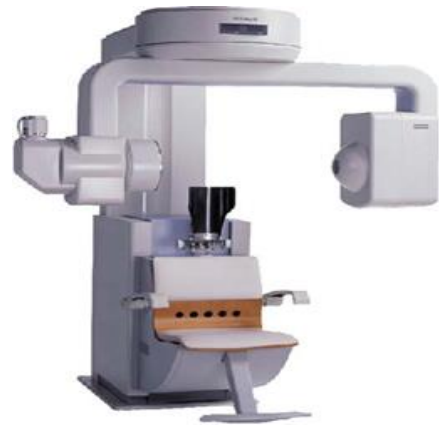

C)

Figure 4. The CBCT devices approved for use in dentistry (A). NewTom 3G (courtesy of Aperio Services); (B) ILUMA (courtesy of IMTEC); (C) CB MercuRay (courtesy of Hitachi Medical Systems America); (D) i-CAT (courtesy of Imaging Sciences); and (E) 3D Accuitomo (courtesy of J. Morita USA). 
The first CBCT device on the market was the NewTom 9000 . This system has 3 possible FOVs as 6, 9 and 12 inches and can produce voxel resolution up to $0.16 \mathrm{~mm}$. The image is taken with the patient in a supine position and the head and leg are imaged in as short a time as 36 seconds.

In the i-CAT system, the image is taken with the patient in an upright sitting position and the scan duration varies between 20 and 40 secs. The main negative feature of this device is that when placing it on the patient, facial tissues are distorted by the chin support. It has been attempted to eliminate this problem with further developments. The 3D Accuitomo device presents a FOV of $1.2 \times 1.6$ inches and the image is formed by focussing only on specific structures. This system was produced through collaboration of Nihon University Dental Faculty with J. Morita Manufacturing.

The most rapid CBCT device to date is the CB MercuRay system which is a large device permitting 3 different FOVs. The scan time is 10 secs. With a $360^{\circ}$ rotation around the patient, a total of 288 2D and 3D images can be formed. The advantage of this system is that the formation of a clear image is facilitated as patient movement is restricted.

The ILUMA system is the most recently developed and is a head and neck imaging CBCT with a fixed FOV. The ILUMA has 2 different versions, the OrthoCAT and the Dental CAT, with 2 different FOV of $7.5 \times 7.5$ inch and $4 \times 6.7$ inch (21).

\section{The Reasons for Artefacts Created in CBCT Systems}

Artefacts created in CBCT technology can be classified as artefacts related to the patient, the scanner and the cone beam, acquired artefacts and artefacts known as skaters which are formed from noise and light scattering (43). Of these, the most frequently seen are artefacts related to movement during scanning of the patient (44). As the image taking duration is prolonged in some cases when it is necessary to increase the 3-D image resolution, patient movement may increase in this process. Generally, patient movement-related artefacts can be classified as respiration, muscle movements, heartbeat and digestion (45).

Some manufacturers have developed special head fixation devices to decrease artefacts $(46,47)$. Donaldson et al conducted studies to determine movement-related artefacts in CBCT and the need for repeated imaging because of this, and it was reported that no artefacts were seen on $95.5 \%$ of images. Those with artefacts were usually the images of patients aged <16 years or >65 years (48).

Scanner-related artefacts are generally seen in the form of a circle originating from insufficient calibration or errors in scanner perception (49). Cone beam-related artefacts are seen in the form of fine lines and vary according to reduced mean partial volume of the data count and the effect of the cone beam. One of the most important causes of artefacts seen on CBCT is the stiffening of the beam. This beam stiffening is seen as a distortion of metallic structures associated with different absorption and as lines emerging between two dense objects. If evaluation is required in respect of artefacts in the teeth or adjacent structures, bean stiffening can reduce the effectiveness of the CBCT (50).

The image quality of the metallic structures seen within the mouth may be significantly impaired and this may affect the diagnosis. In a study by Benic et al (51) to determine the density and geometric form of artefacts formed from implant materials, it was reported that artefacts were always seen in the finishing of titanium implants in whichever region they were placed. To prevent these artefacts being seen on CBCT scans, the patient must be positioned correctly and in particular, a good knowledge of the optimum slice parameters is necessary (52).

\section{Conclusion}

CBCT technology is a 3-dimensional imaging method which was developed to visualize the structures in the maxillofacial region. When studies over the last decade are examined, it can be seen that encouraging results have been obtained in respect of diagnosis from the use of this method in dentistry. Interpretation of studies made of CBCT have shown that with this method, significant advances have been made in the diagnostic process, treatment planning and the evaluation of results. In cases where periapical, panoramic and occlusal films remain insufficient, the use of CBCT can be recommended to reduce complications to a minimum.

\section{Acknowledgments}

The authors deny any conflicts of interest related to this study. 


\section{References}

1. Eisenberg RL. Radiology: An Illustrated History. St Louis: Mosby-Year Book Inc.1996.

2. Macleod I, Heath N. Cone-Beam Computed Tomography (CBCT) in Dental Practice. Dental and Maxillofacial Radiology 2008;35:590-8. Crossref

3. Kalabalık F, Tarım Ertas E. Artefact Types and Their Causes in Cone-Beam Computed Tomography. J Dent Fac Ataturk Uni. 2016;15:162-7.

4. White SC, Pharoah MJ. The Evolution and Application of Dental Maxillofacial Imaging Modalities. Dent Clin North Am. 2008;52(4):689-705. Crossref

5. Farman AG, Scarfe WC. The Basics of Maxillofacial Cone Beam Computed Tomography. Semin Orthod. 2009;15(1):2-13. Crossref

6. Scarfe WC, Farman AG. Cone-Beam Computed Tomography. White SC, Pharoah M.J. Oral Radiology: Principles and Interpretation. Mosby, 2009, 225-243.

7. Falakaloglu $S$, Veis $A$. Determining the size of the mental foramen: A cone-beam computed tomography study. Int Dent Res 2017;7:20-5. Crossref

8. Tsiklakis K, Donta C, Gavala S, Karayianni K, Kamenopoulou $\mathrm{V}$, Hourdakis $\mathrm{CJ}$. Dose reduction in maxillofacial imaging using low dose Cone Beam CT. Eur J Radiol 2005;56:413-7. Crossref

9. Aktuna Belgin C, Adiguzel O, Bud M, Colak M, Akkus Z. Mandibular Buccal Bone Thickness In Southeastern Anatolian People: A Cone-Beam Computed Tomography Study. Int Dent Res 2017;7:6-12. Crossref

10. Gibbs SJ. Effective dose equivalent and effective dose: comparison for common projections in oral and maxillofacial radiology. Oral Surg Oral Med Oral Pathol Oral Radiol Endod. 2000; 90: 538-45. Crossref

11. Scarfe WC, Farman AG, Sukovic P. Clinical applications of cone-beam computed tomography in dental practice. J Can Dent Assoc 2006; 72: 75-80.

12. Ngan DCS, Kharbanda OP, Geenty JP, Darendeliler MA. Comparison of radiation levels from computed tomography and conventional dental radiographs. Aust Dent J 2003; 19: 67-75.

13. Mah JK, Danforth RA, Bumann A, Hatcher D. Radiation absorbed in maxillofacial imaging with a new dental computed tomography device. Oral Surg Oral Med Oral Pathol Oral Radiol Endod 2003; 96: 508-13. Crossref

14. Li G. Patient radiation dose and protection from cone-beam computed tomography. Imaging Science in Dentistry 2013;43: 63-9. Crossref

15. Honda K, Larheim TA, Maruhashi K, et al. Osseous abnormalities of the mandibular condyle: diagnostic reliability of cone beam computed tomography compared with helical computed tomography based on an autopsy material. Dentomaxillofac Radiol. 2006;35:152-157. Crossref

16. Hashimoto $K$, Kawashima S, Araki $M$, et al. Comparison of image performance between conebeam computed tomography for dental use and four-row multidetector helical CT. J Oral Sci. 2006;48:27-34. Crossref

17. Kapila SD. Contemporary Concepts of Cone Beam Computed Tomography in Orthodontics. Cone Beam Computed Tomography in Orthodontics: Indications, Insights, and Innovations, 2014.

18. Heiland $M$, Schulze $D$, Blake $F$, et al. Intraoperative imaging of zygomaticomaxillary complex fractures using a 3D C-arm system. Int J Oral Maxillofac Surg. 2005;34:369-375. Crossref

19. Guerrero $M E$, Jacobs $R$, Loubele $M$, Schutyser $F$, Suetens $P$, Van Steenberghe D. State-of-the-art on Cone Beam CT Imaging for Preoperative Planning of Implant Placement. Clin Oral Invest. 10(1):1-7, 2006. Crossref
20. Cotton TP, Geisler TM, Holden DT, Schwartz SA, Schindler WG. Endodontic applications of cone-beam volumetric tomography. J Endod 2007; 33: 1121-32. Crossref

21. Palomo J. M., Kau CH, Bahl Palomo L, and Hans MG. Threedimensional Cone Beam Computerized Tomography in Dentistry. Dentistry today, 2006.

22. Danforth RA, Dus I, Mah JJ. 3-D volume imaging for dentistry: a new dimension. Calif Dent Assoc 2003; 31: 817-23.

23. Ertas ET, Arslan H, Capar ID, Gök T, Ertas H. Cone-Beam Computerized Tomography in Endodontics. EU Faculty of Dentistry Journal 2014;24:113-8.

24. 24.Spector L. Computer-aided Dental Implant Planning. Dent Clin North Am. 52(4):761-775, 2008. Crossref

25. 25. Mah JK, Enrico R, Jorgensen M. Management of impacted cuspids using 3-D volumetric imaging. J Calif Dent Assoc 2003; 31: 835-41.

26. Kau $\mathrm{CH}$, Richmond $\mathrm{S}$, Palomo JM, et al. Three-dimensional cone beam computerized tomography in orthodontics. J Orthod. 2005;32:282-293. Crossref

27. Fullmer JM, Scarfe WC, Kushner GM, Alpert B, Farman AG. Cone Beam Computed Tomographic Findings in Refractory Chronic Suppurative Osteomyelitis of the Mandible. $\mathrm{Br} \mathrm{J}$ Oral Maxillofac Surg. 2007:45(5):364-371. Crossref

28. Madrigal C, Ortega R, Meniz C, Quiles JL. Study of Available Bone for Interforaminal Implant Treatment Using ConeBeam Computed Tomography. Med Oral Patol Oral Cir Bucal. 2008;13(5):307-12.

29. Cevidanes SHL, Styner AM, Proffit RW. Image analysis and superimposition of 3-dimensional cone-beam computed tomography models. Am J Orthod Dentofacial Orthop 2006; 129:611-8. Crossref

30. Honey $\mathrm{OB}$ et al. Accuracy of cone beam computed tomography imaging of temporomandibular joint: Comparisons with panoramic radiology and linear tomography. Am J Dentofacial Orthop 2007; 430-8.

31. Zarei $M$ et al. In-vitro evaluation of the effect of canal curvature on adaptation of gutta-percha in canals obturated with HEROfill system by CBCT. J Oral Sci 2011; 1: 43-50.

32. Sukovic P. Cone beam computed tomography in craniofacial imaging. Orthod Craniofac Res 2003; 6(Suppl 1):31-6. Crossref

33. Ziegler CM, Woertche R, Brief J, Hassfeld S. Clinical indications for digital volume tomography in oral and maxillofacial surgery. Dentomaxillofac Radiol 2002; 31(2):126-30. Crossref

34. Cohnen M, Kemper J, Mobes O, Pawelzik J, Modder U. Radiation dose in dental radiology. Eur Radiol 2002; 12(3):634-7. Crossref

35. Schulze $D$, Heiland $M$, Thurmann $H$, Adam G. Radiation exposure during midfacial imaging using 4- and 16-slice computed tomography, cone beam computed tomography systems and conventional radiography. Dentomaxillofac Radiol 2004; 33(2):83-6. Crossref

36. Razavi T, Palmer RD, Davies J, Wilson R, Palmer PJ. Accuracy of measuring the cortical bone thickness adjacent to dental implants using cone beam computed tomography. Clin Oral Implants Res 2010;23:718-25. Crossref

37. Adibi S, Zhang W, Servos T, N. O'Neill P. Cone Beam Computed Tomography in Dentistry: What Dental Educators and Learners Should Know. Journal of Dental Education 2012;76(11): 1437-1442.

38. Cohnen M, Kemper J, Mobes O, Pawelzik J, Modder U. Radiation dose in dental radiology. Eur Radiol 2002; 12(3):634-7. Crossref

39. Horner K1, Islam M, Flygare L, Tsiklakis K, Whaites E. Basic principles for use of dental cone beam computed tomography: consensus guidelines of the European Academy of Dental and Maxillofacial Radiology. Dentomaxillofac Radiol. 2009;38(4):187-95. Crossref

40. Farman AG. Self-referral: an ethical concern with respect to multidimensional imaging in dentistry? J Appl Oral Sci 2010. 
41. Valentin J. The 2007 recommendation of the International Commission on Radiological Protection, publication 103. Ann ICRP 2007;37:1-332.

42. Carter L, Farman AG, Geist J, Scarfe WC, Angelopoulos C, Nair MK, et al. American Academy of Oral Maxillofacial Radiology executive opinion statement on performing and interpreting diagnostic cone beam computed tomography. Oral Surg Oral Med Oral Pathol Oral Radiol Endod 2008;106(4):561-2. Crossref

43. De Man B, Nuyts J, Dupont P, Marchal G, Suetens P. Metal streak artifacts in X-ray computed tomography: A simulation study. IEEE Trans Nuc Sci 1999;46:691-96. Crossref

44. Schulze R, Heil U, Gross D, Bruellmann DD, Dranischnikow $\mathrm{E}$, Schwanecke U. Artefacts in CBCT: a review. Dentomaxillofac Radiol 2011;40:265-73. Crossref

45. Li G, Citrin D, Camphausen K, Mueller B, Burman C, Mychalczak $B$, ve ark. Advances in $4 D$ medical imaging and 4D radiation therapy. Technol Cancer Res Treat 2008;7:6781. Crossref

46. Hanzelka T, Foltan R, Horka E, Sedy J. Reduction of the negative influence of patient motion on quality of CBCT scan. Med Hypotheses 2010;75:610-2. Crossref

47. Angelopoulos C, Scarfe WC, Farman AG. A comparison of maxillofacial CBCT and medical CT. Atlas Oral Maxillofac Surg Clin North Am 2012;20:1-17. Crossref

48. Donaldson K, O'Connor S, Heath N. Dental cone beam CT image quality possibly reduced by patient movement. Dentomaxillofac Radiol 2013;42:91866873. Crossref

49. Gross D, Heil U, Schulze R, Schoemer E, Schwanecke U. GPU-Based Volume Reconstruction from Very Few Arbitrarily Aligned X-Ray Images. SIAM J Sci Comp 2009;31:4204-21. Crossref

50. Mozzo P, Procacci C, Tacconi A, Martini PT, Andreis IA. A new volumetric $C T$ machine for dental imaging based on the cone-beam technique: preliminary results. Eur Radiol 1998; 8: 1558-64. Crossref

51. Benic GI, Sancho-Puchades M, Jung RE, Deyhle $H$, Hammerle $\mathrm{CH}$. In vitro assessment of artifacts induced by titanium dental implants in cone beam computed tomography. Clin Oral Implants Res 2013;24:378-83. Crossref

52. Kaya BU. Application Areas of Cone-Beam Computerized Tomography in Endodontics. EU Faculty of Dentistry Journal. 2012; 33(1): 21-31. 